\title{
Integration of glass transition in freeze-drying kinetic modelling to improve protein stability
}

\author{
Passot, S., Tréléa, C., Fonseca, F., Barbouche, N., Marin, M. \\ INRA, Unité Mixte de Recherche de Génie et Microbiologie des Procédés Alimentaires, \\ 78850 Thiverval Grignon, France (spassot@grignon.inra.fr)
}

\begin{abstract}
Our objective was to provide an interactive software tool for freeze-drying cycle optimization, taking into account a relevant quality criterion. To determine this quality criterion, the relevance of glass transition temperature for predicting stability of freeze-dried protein was investigated. Keywords : freeze-drying, glass transition, protein stability, modelling
\end{abstract}

\section{Introduction}

Freeze-drying is widely used to improve long-term storage stability of proteins, active ingredients, and microorganisms but remains a time- and energy-intensive process. As minimizing the production costs has become a growing concern, the challenge is to optimize cycle conditions by shortening drying times, while retaining essential properties of a freezedried product including cake structure, preservation of the active ingredient.

The glass transition temperature of the maximally freeze-concentrated phase ( $\left.\mathrm{Tg}^{\prime}\right)$ has been identified as a key parameter of successful freeze-drying and protein stability. It is generally assumed that the rate of protein unfolding is fast above Tg' but very slow in the solid state below Tg' [1]. The product temperature must be kept below the glass transition temperature all along the process. The product temperature results from the shelf temperature and the chamber pressure applied, and is not directly controlled during freeze-drying process. In practice, the appropriate shelf temperature and chamber pressure conditions are frequently established empirically in a "trial-and-error" experimental approach and many manufacturing processes are far from optimal. Theoretical modelling can provide a better understanding of the impact of process and formulation variation on cycle time and product temperature history and, thereby, facilitate process development.

\section{Experimental}

Aliquots of the two proteins studied (named A and B), supplied by bioMérieux were formulated at $1 \mu \mathrm{g} / \mathrm{mL}$ in a protective medium including $4 \%$ of polyvinylpyrrolidone, $1 \%$ of sucrose and $10 \mathrm{mM}$ of Tris buffer (pH 7.8). 18 freeze-drying cycles were performed by using various combinations of shelf temperature and chamber pressure to obtain different values of product temperature during primary drying. The concentrations of the proteins $\mathrm{A}$ and $\mathrm{B}$, corresponding to a measurement of the antigenic activity, were assessed by a quantitative enzyme-linked immunoabsorbent assay (ELISA) developed by bioMérieux. The antigenic activity was measured immediately after freeze-drying and after 6 months of storage at $4{ }^{\circ} \mathrm{C}$.

A software making it possible the interactive selection of the process operating conditions (shelf temperature profile and chamber pressure profiles) and simultaneous monitoring of the critical product quality parameters were developed [2]. The software was based on a simple yet accurate one-dimensional dynamic model of heat and mass transfer with associated product quality indicators (glass transition temperature) and experimentally validated in a wide range of operating conditions relevant for the freeze-drying of pharmaceutical products.

\section{Results}

The protective medium (4\% of PVP, $1 \%$ of sucrose and $10 \mathrm{mM}$ of Tris- $\mathrm{HCl}$ ) exhibited a $\mathrm{Tg}$ ' of $-28^{\circ} \mathrm{C}$. After freeze-drying, significant shrinkage of the dried product was observed when the product temperature during primary drying was higher than $-22^{\circ} \mathrm{C}$. Immediately after freeze-drying, the antigenic activity recovery was around $70 \%$ whatever the process 
conditions applied. After 6 months of storage, the losses of biological activity increased when primary drying was performed above Tg' (Figure 1). The increased of molecular mobility when the product changed from the amorphous state to the viscous state during the process may have caused protein structural change which were reversible upon dissolution but which predisposed the proteins to more rapid degradation during storage.

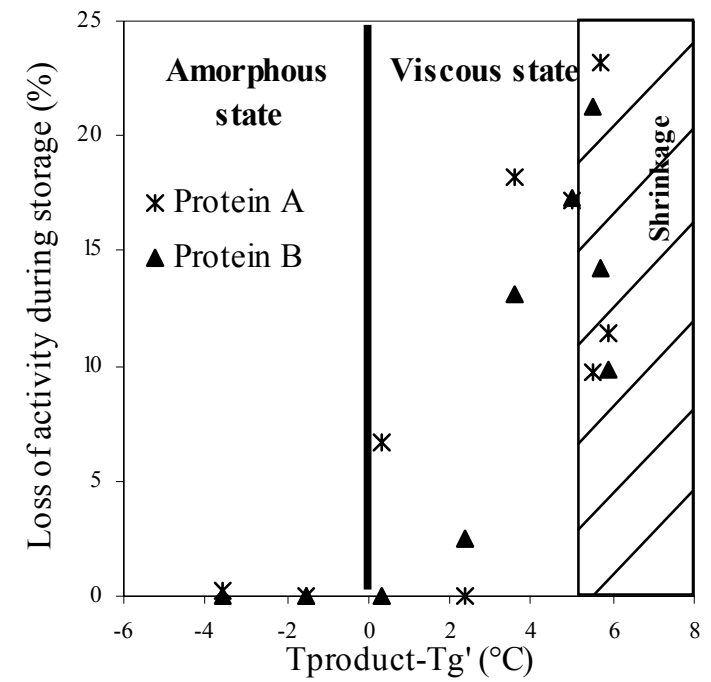

Figure 1: Loss of antigenic activity of the two proteins after 6 months of storage at $4^{\circ} \mathrm{C}$ as a function of the product temperature obtained during sublimation
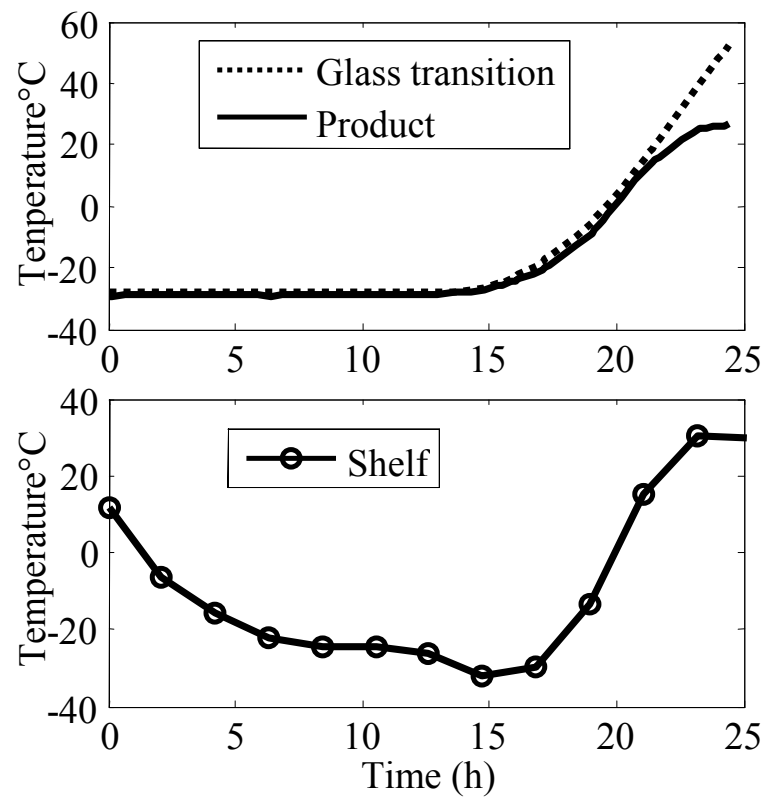

Figure 2: Profile of shelf and product temperatures obtained from the cycle optimization (chamber pressure was fixed at $10 \mathrm{~Pa}$ )

Freeze-drying simulations were thus carried out with the constraint of maintaining the product temperature as close as possible but slightly lower than the glass transition temperature all along the drying step. An optimised cycle was defined by applying shelf temperature and chamber pressure profiles with high temperature value initially and lower values towards the end of primary drying (Figure 2). The usual industrial practices, which consist in performing sublimation at a constant shelf temperature, often results in either long processing times or risk area for product stability when the product temperature exceeds the $\mathrm{Tg}$ ' at the end of primary drying.

This interactive software appears as a useful tool to adapt the couple formulation/process and to predict product stability. While changing the operating conditions, the user monitors process parameters relevant for productivity and product quality: product temperature and glass transition temperature at critical points and residual moisture content.

\section{Acknowledgments}

This work was financially supported by the European Community through the Competitive and Sustainable Growth Program "LYOPRO" (GRD1-2001-40259-RTD). We gratefully acknowledge all the members of this European project and especially Dominique Rolland, Muriel Alarcon-Lorca and Michel Rapaud from bioMérieux.

\section{References}

[1] Pikal, M. J. (1999). Mechanisms of protein stabilization during freeze-drying and storage : The relative importance of thermodynamic stabilization and glassy state relaxation dynamics. In Rey, L. \& May, J. C. (ed.). Freeze-drying / Lyophilisation of pharmaceutical and biological products. Marcel Dekker, NeW York, 161-198.

[2] Trelea, I. C.; Passot, S.; Fonseca, F.; and Marin, M. (2006). An interactive tool for freeze-drying cycle optimization including quality criteria, Drying Technology (accepted) 